\title{
QUININE AMBLYOPIA TREATED BY STELLATE GANGLION BLOCK*
}

\author{
BY \\ J. MCLENACHAN \\ Royal Infirmary, Oldham, Lancs.
}

THIS case was considered worthy of publication for three reasons. First, the amount of quinine sulphate taken was $12 \mathrm{~g}$., or at least twice what is regarded as a fatal dose. Secondly, there was a dramatic recovery of vision, apparently following upon bilateral stellate ganglion infiltration with local anaesthetic. Thirdly, the ophthalmoscopic appearances did not conform to those usually described in quinine amblyopia.

\section{Case Report}

Two teaspoonfuls of pulv. quinine sulphate were taken by a young woman as an abortifacient. She was admitted to the Casualty Department some 14 hours later, in a drowsy state, with complete loss of vision, tinnitus, and slight deafness, and gastric lavage was carried out immediately.

Examination.-There was complete loss of perception of light in each eye. The pupils were maximally dilated and did not react to light. The whole impression of the fundi was that of congestion - the veins were dilated, and one or two white fluffy exudates were noted in proximity to them. The arteries were of normal calibre and the disc margins hazy, there was no foveal reflex, and the fundal colour was dark red.

Treatment.-Although the ophthalmoscopic appearance did not suggest that vasoconstriction was, at the moment, playing a part, it was decided to give a vasodilator as the traditional concept is that the harmful effect of quinine on the eye is due to a supposed vasoconstriction. $50 \mathrm{mg}$. Priscol (benzyl-imidazoline) were given intramuscularly and repeated 4-hrly. In addition $1,000 \mu \mathrm{g}$. Cytamen (Vit. $\mathrm{B}_{12}$ ) were given intramuscularly in the vague hope of alleviating any nervone damage. Finally, as the patient was extremely distressed by the loss of vision, $50 \mathrm{mg}$. Largactil were given intramuscularly.

As there was no improvement in a few hours' time it was decided to follow the techniques of Redslob, Warter, and Isch (1947) and to try infiltration of both stellate ganglia with a local anaesthetic. The stellate ganglia were blocked with procaine at one hour intervals-there were no adverse effects and a transient Horner's syndrome was observed in each case. The patient fell asleep shortly afterwards and when she awoke next morning her vision had made a dramatic recovery in that she was able to recognize faces and colours. A second bilateral infiltration of the stellate ganglia was carried out and a few hours later the vision was recorded as 6/9 in each eye.

Some 24 hours later visual field estimates were carried out. There was a marked generalized constriction on perimetry to within $15^{\circ}-20^{\circ}$ of fixation. The edge of the field was quite sharp for different sizes of test objects. Red, green, and blue were distinguishable and their constriction was in proportion to that of the white. 
Result.-Visual field recordings on the perimeter were made every 2 or 3 days and a maximal recovery was reached after 4 weeks. By this time the field extended to $50^{\circ}$ nasally and temporally, above $45^{\circ}$ and below $35^{\circ}$, with a $5 / 330$ white test object. The fields for red and green were in proportion. The only noteworthy feature was that the temporal fields remained constricted whilst the nasal fields eventually made a full recovery. The patient complained of this loss of temporal field.

\section{Discussion}

The possibilities are, first, that the recovery of sight was independent of the treatment given. Spontaneous recovery does take place in quinine amblyopia, although the rate and extent of recovery appears to be less than in this case. Cooper (personal communication) has described a case of amblyopia following the ingestion of $75 \mathrm{gr}$. quinine. Vasodilators and infiltration of the cervical ganglia were given on the third day and a maximal visual acuity of 6/9 partly was not reached until 4 weeks later. In that case there was no immediate response to the cervical ganglion blockage. A comparison of Cooper's case and that here reported seems to indicate that early treatment, as described, is beneficial.

Secondly, the recovery might have been due to the administration of intramuscular Priscol (benzyl-imidazoline) and/or the vitamin $\mathbf{B}_{12}$. The toxic effect of large doses of quinine on the heart muscle, causing marked lowering of the blood pressure, may be counteracted by the action of Priscol in stimulating the myocardium and dilating the coronary vessels. Simonelli (1947) reported favourable results which followed the administration in cases of toxic amblyopia. The absence of any vasoconstrictor makes its local effect on the eye difficult to explain. There is some rationale in giving large doses of vitamin $B_{12}$, as its protective action on the nucleoproteins of the ganglion cells of the nervous system has been proved in other cases of amblyopia.

If the improvement of vision, which appears to justify Redslob's description of it as dramatic, is due to the stellate ganglion blocking, then what is the mechanism? Clinically there was no retinal artery narrowing, such as the text-books describe-quite the reverse, for the fundal appearance was that of oedema and congestion.

Földi, Szeghy, and Sanda (1962) claim a relief of retinal congestion and a concomitant visual improvement in papilloedema and other congestive retinal conditions after stellate ganglion block by procaine. They are unable to explain the improvement as being due to haemodynamic changes and conclude by postulating that the blockage of the stellate ganglia relieved a spasm of the lymphatic vessels.

\section{REFERENCES}

Foldi, M., Szeghy, G., and SANDA, E. (1962). Lancet, 1, 512.

REDSLOB, E., WARTER, J., and ISCH, F. (1947). Rev. oto-neuro-ophtal., 19, 187.

Simonelli, M. (1947). Riv. Oftal. ital. 2, 174. 